\title{
A novel mutation, Ala315Ser, in FGFR2: a gene-environment interaction leading to craniosynostosis?
}

\author{
David Johnson ${ }^{1,2}$, Steven A Wall ${ }^{2}$, Susan Mann ${ }^{2,3}$ and Andrew OM Wilkie ${ }^{1,2}$ \\ ${ }^{1}$ Institute of Molecular Medicine, John Radcliffe Hospital, Oxford; ${ }^{2}$ Department of Plastic and Reconstructive Surgery \\ and Oxford Craniofacial Unit, Raddliffe Infirmary, Oxford; ${ }^{3}$ Department of Anaesthetics, John Radcliffe Hospital, \\ Oxford, UK
}

Mutations in the fibroblast growth factor receptor 1, 2 and 3 (FGFR1, -2 and -3 ) and TWIST genes have been identified in several syndromic forms of craniosynostosis. There remains, however, a significant number of patients with non-syndromic craniosynostosis in whom no genetic cause can be identified. We describe a novel heterozygous mutation of FGFR2 (943G $\rightarrow$ T, encoding the amino acid substitution Ala315Ser) in a girl with non-syndromic unicoronal craniosynostosis. The mutation is also present in her mother and her maternal grandfather who have mild facial asymmetry but do not have craniosynostosis. None of these individuals has the Crouzonoid appearance typically associated with FGFR2 mutations. However, the obstetric history revealed that the proband was in persistent breech presentation in utero and was delivered by Caesarean section, at which time compression of the skull was apparent. We propose that this particular FG FR2 mutation only confers a predisposition to craniosynostosis and that an additional environmental insult (in this case foetal head constraint associated with breech position) is necessary for craniosynostosis to occur. To our knowledge, this is the first report of an interaction between a weakly pathogenic mutation and intrauterine constraint, leading to craniosynostosis. European Journal of Human Genetics (2000) 8, 571-577.

Keywords: craniosynostosis; FGFR2; intrauterine environment; mutation; breech presentation; foetal head constraint

\section{Introduction}

Craniosynostosis, the premature fusion of the calvarial sutures, is an important congenital abnormality occurring in approximately 1 in 2500 live births. This disorder occurs in isolation in the majority of cases but can also be associated with additional clinical signs, constituting a syndrome. To date, heterozygous mutations of four genes have been identified as common causes of syndromic craniosynostosis: the fibroblast growth factor receptors 1, -2 and -3 (FGFR1, FGFR2, FGFR3) and the transcription factor TW IST. ${ }^{1,2}$

In the majority of cases, mutations of these genes are associated with obvious syndromes, the most common being

Correspondence: Dr Andrew OM Wilkie, Institute of Molecular Medicine, John Radcliffe Hospital, Headington, Oxford, OX3 9DS, UK. Tel: +44 1865 222619; Fax: +44 1865 222500;

E-mail: awilkie@enterprise.molbiol.ox.ac.uk

Received 1 March 2000; accepted 31 March 2000 the Apert (FGFR2), Crouzon (FGFR2 or FGFR3), Pfeiffer (FGFR1 or FGFR2) and Saethre-Chotzen syndromes (TW IST). Most patients with FGFR2 mutations are readily picked out by a characteristic 'Crouzonoid' facial appearance that includes exorbitism, midface hypoplasia and a prominent beaked nose. These FGFR2 mutations are clustered in two exons, Igllla and Iglllc, which together form the third extracellular immunoglobulin-like domain of the protein. Alternative splicing between two exons, Iglllb and Iglllc, generates two receptor isoforms (KGFR and BEK respectively), with different ligand binding properties. ${ }^{3,4}$ No mutations have been identified in the Iglllb exon in any disorder.

Most patients with craniosynostosis do not, however, have obvious syndromic features, making accurate diagnosis and genetic counselling more difficult, particularly because nonsyndromic craniosynostosis is likely to be aetiologically heterogeneous. Up to $30 \%$ of such patients with coronal 
craniosynostosis have a specific mutation in FGFR3 (Pro250Arg) that is more reliably identified by genetic testing than by clinical features. ${ }^{5-7}$ Mutations of FGFR2 are much rarer in non-syndromic patients, but a small number of FGFR2 mutations have been identified in individuals with mild, atypical or more variable phenotypes. ${ }^{8-12}$

In the majority of non-syndromic patients, no genetic cause can be identified. The increased prevalence of craniosynostosis associated with multiple pregnancy and oligohydramnios, and the anecdotal history of restricted foetal movement reported in some pregnancies of affected children, led to the proposal that foetal head constraint was an important cause of craniosynostosis. ${ }^{13-16}$ Experiments on animals lend additional support to this proposal. ${ }^{17}$ Despite these observations a well documented instance demonstrating the synergistic interaction between genetic and intrauterine factors has not previously been reported.

We describe a novel heterozygous mutation of FGFR2, Ala315Ser, in a patient with non-syndromic unicoronal craniosynostosis. The mutation, located in the third immunoglobulin-like domain (IgllIc), is also present in the patient's mother and maternal grandfather, both of whom have mild facial asymmetry but do not have craniosynostosis. The obstetric history revealed that the patient had a persistent breech presentation and required delivery by Caesarean section: compression of the skull was apparent at birth. We propose that this FGFR2 mutation predisposes to craniosynostosis but requires an additional environmental insult (in this case foetal head constraint associated with breech position) for the disorder to occur. Phenotypically this represents one of the mildest FGFR2 mutations yet described.

\section{Materials and methods \\ Reverse transcriptase PCR (RT-PCR) and CDNA preparation}

RNA extraction and cDNA preparation was performed as previously described. ${ }^{18}$ Primers for RT-PCR were synthesised by Genosys Biotechnologies (Lewes, East Sussex, UK). A $889 \mathrm{bp}$ CDNA product of FGFR2 was amplified using primer pair 2F (5'-GCCATCTCATCCGGAGATG-3') and 8R (5'-GGATACGTTTGGTCAGCTTGTG-3'), corresponding to sequences in exons 4 and 9 (=IgllIc) respectively (exon numbering as previously reported ${ }^{19}$ ). RT-PCR was performed in a volume of $25 \mu \mathrm{l}$ that contained $2 \mu \mathrm{l}$ cDNA prepared from fibroblasts and employed the Expand Long Template PCR system (Boehringer Mannheim, Pampisford, Cambridgeshire, UK) using buffer 3 . The reaction conditions consisted of $94^{\circ} \mathrm{C}$ for $2 \mathrm{~min}$ followed by $10 \mathrm{cycles}$ of $94^{\circ} \mathrm{C}$ for $1 \mathrm{~min}, 55^{\circ} \mathrm{C}$ for $30 \mathrm{~s}$, $68^{\circ} \mathrm{C}$ for $3 \mathrm{~min}$, followed by 20 cycles of $94^{\circ} \mathrm{C}$ for $1 \mathrm{~min}, 60^{\circ} \mathrm{C}$ for $30 \mathrm{~s}, 68^{\circ} \mathrm{C}$ for $3 \mathrm{~min}$ (with a $20 \mathrm{~s}$ increment every cycle) followed by a final step of $68^{\circ} \mathrm{C}$ for $7 \mathrm{~min}$.

\section{DNA sequencing and mutation confirmation}

RT-PCR products for sequencing were gel-purified using the QIAquick gel extraction kit (Qiagen, Crawley, West Sussex, UK). Cycle sequencing was performed manually by use of the Thermosequenase Cycle Sequencing Kit (Amersham, Little Chalfont, Buckinghamshire, UK). Primers used for sequencing included the RT-PCR primers $2 \mathrm{~F}$ and $8 \mathrm{R}$ as well as an additional exon 7 primer E7F (5'-CCACATCCAGTGGATCAAGC-3'). Sequence changes were confirmed by diagnostic restriction enzyme digestion ( $5 \mu \mathrm{l}$ PCR product in a total volume of $15 \mu \mathrm{l}$ ) performed on a $225 \mathrm{bp}$ genomic PCR product generated using the exon 9 primer pair R2I9F/ R2I9R. ${ }^{20}$ The Stul site created by the mutation yields fragments of $174 \mathrm{bp}$ and $51 \mathrm{bp}$. cDNA numbering is based on a previous report, ${ }^{21}$ but starts at the initiator methionine codon.

\section{Results \\ Molecular studies}

We performed a complete screen of the coding region of FGFR2 in patients with non-syndromic craniosynostosis (manuscript in preparation) using an RNase cleavage assay. Patient CRS53 (IV-2 in the pedigree, Figure1A), who presented with unicoronal non-syndromic craniosynostosis, exhibited an abnormal cleavage fragment for the 2F-8R cDNA product. DNA sequencing identified a 943G $\rightarrow T$ transversion (Figure1B) corresponding to the amino acid substitution Ala315Ser. The mutation creates a Stul restriction site and destroys a Fnu4HI restriction site, which we exploited to confirm the identity of the mutation and to screen additional individuals. The presence of the Stul site confirmed this mutation in the patient and demonstrated that the same mutation was present in her mother, III-2, and maternal grandfather, II-2, neither of whom have craniosynostosis (Figure1C). Samples from a further 91 unrelated patients with non-syndromic craniosynostosis as well as 542 normal individuals (1084chromosomes) digested normally with Fnu4HI and hence were negative for this mutation, as well as any other mutation of either the Ala314 or Ala315 codons.

\section{Case report}

Patient CRS53, a girl of north European origin born to nonconsanguineous parents, was assessed at the age of 6 months because of plagiocephaly. There was no family history of craniosynostosis. The obstetric history revealed that the patient had been in persistent breech position, first confirmed by ultrasound scan at 34 weeks of gestation and subsequently on follow up scans at 37 and 39 weeks. The breech position was noted to beflexed on the initial scan, but extended on the subsequent scans. Liquor volume was initially normal but slightly below average for dates on the subsequent scans. Foetal head circumference was consistently bel ow the 5th centile but an abnormal head shape was 


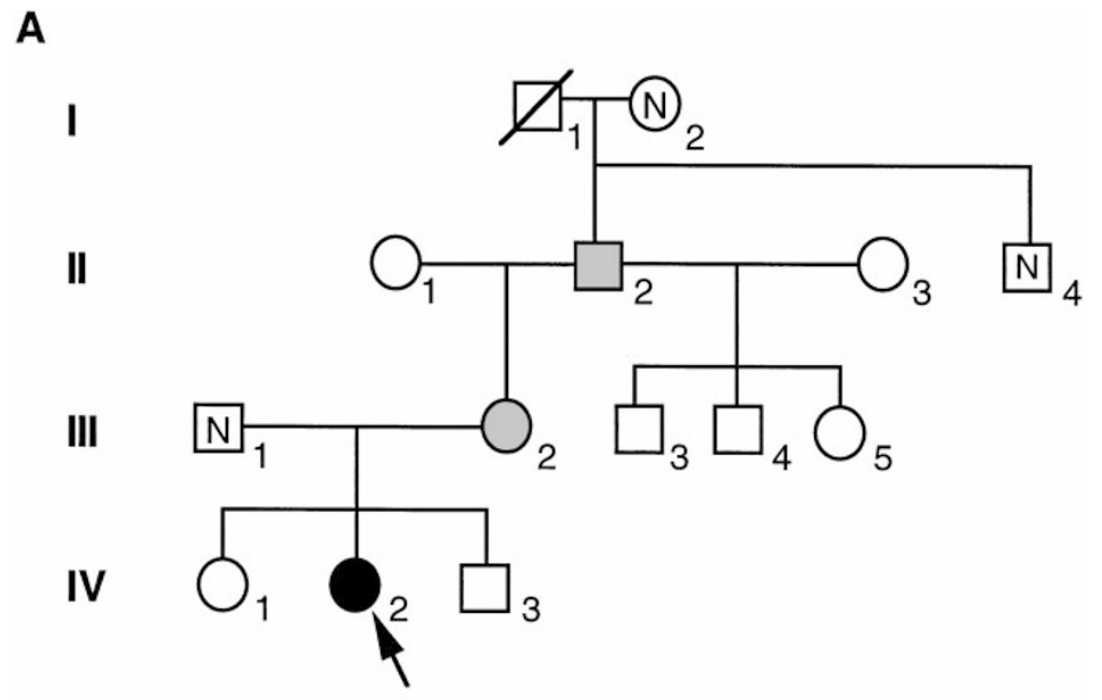

B

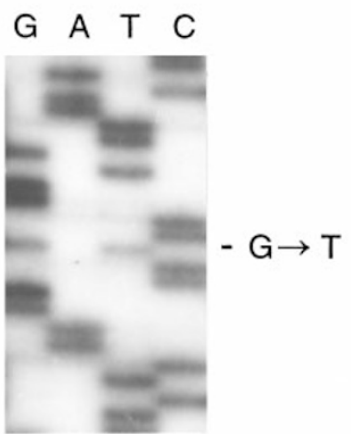

C I-2 II-2 III-2 III-1 IV-2

Figure 1 Identification of the Ala315Ser mutation in FGFR2. A Pedigree showing the proband IV-2 with unicoronal synostosis (black fill). Shaded fill identifies other individuals testing positive for the mutation; $\mathrm{N}$ identifies genetically confirmed unaffected individuals; no fill signifies not genetically tested. B DNA sequence of proband demonstrating a heterozygous $943 G \rightarrow T$ substitution in FGFR2. C Diagnostic restriction enzyme digestion with Stul. The presence of the Stul site confirms the mutation in the proband, her mother (III-2) and maternal grandfather (II-2).

not apparent. She was delivered by elective Caesarean section at 39 weeks gestation. At birth the parents reported that the child's hips were flexed and both feet were pressing against the right side of her head. The neonatal paediatric assessment recorded the presence of 'bilateral positional talipes' (subsequently treated successfully by physiotherapy) and 'slight facial asymmetry'.

Examination in the craniofacial clinic revealed anterior plagiocephaly. The right side of the forehead was flat with a recessed and elevated right eyebrow. The left side of the forehead was bossed, the right malar region was prominent together with an anteriorly positioned right ear and facial asymmetry. A right-sided unicoronal craniosynostosis was confirmed by CT scan (Figure2). She underwent surgery for fronto-orbital advancement, which was abandoned on two occasions owing to intra-operative haemoglobinuria. A blood transfusion reaction was excluded on haematological testing and successful surgery was subsequently performed with use of al ternative anaesthetic agents.

Figure 3 shows the facial features of the proband (IV-2), her mother (III-2), and maternal grandfather (II-2). The proband demonstrates typical features of right-sided unicoronal craniosynostosis with facial asymmetry and mild hypertelorism. Her mother and grandfather both have mild facial asymmetry with hypertelorism, both having an interpupillary distance of $6.5 \mathrm{~cm}$ (approximately 97th centile). In addition the proband's mother has mild orbital dystopia. However, neither showed clinical or radiological features of craniosynostosis. There was no exorbitism, midface hypoplasia, oropalatal defect, or ear abnormality in any of these three individuals. All had fifth finger clinodactyly and broad halluces; these features were also present in the grandfather's mother (I-2) who tested negative for the FGFR2 mutation (Figure 1C) and so were considered to be coincidental. 

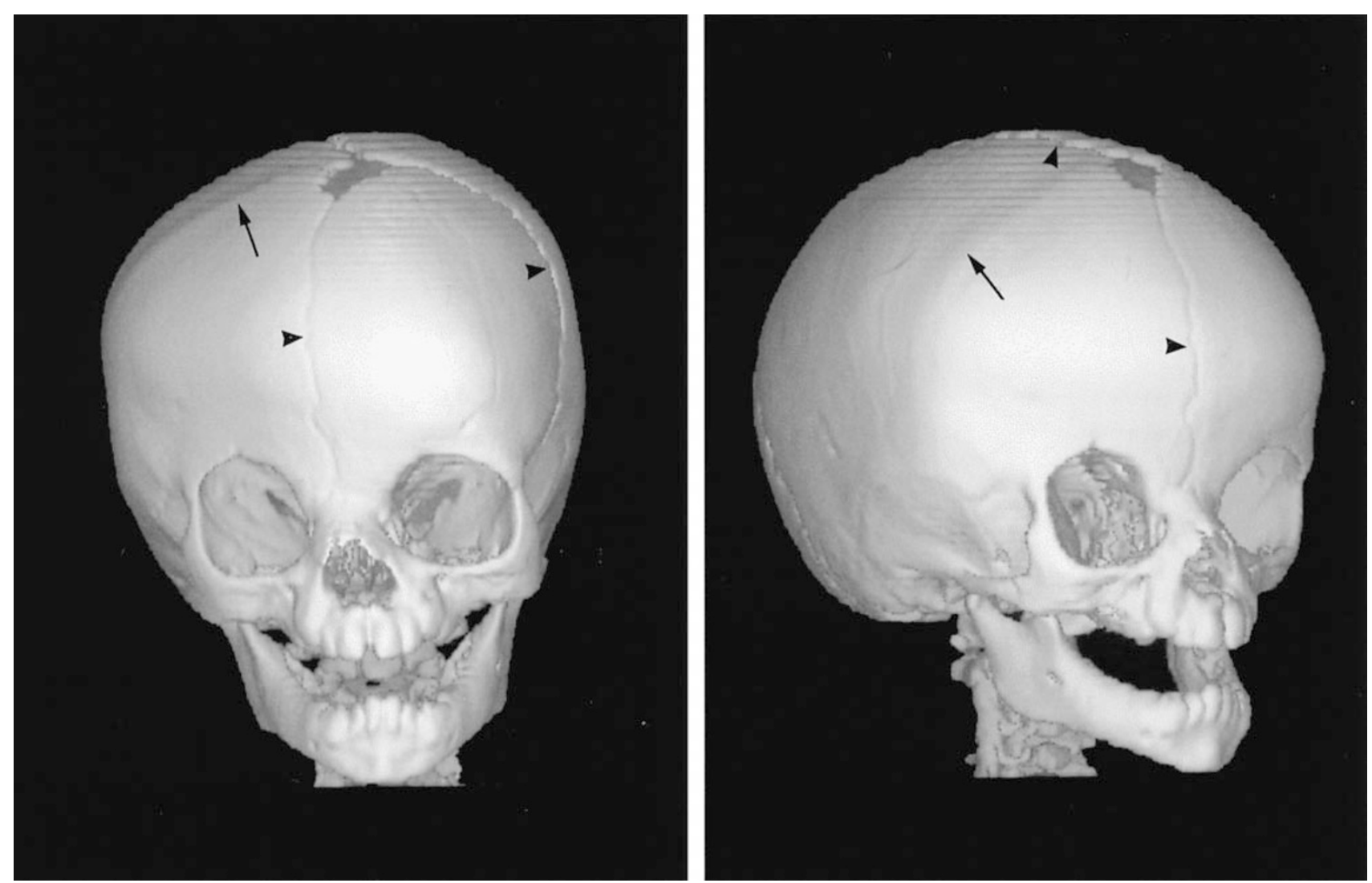

Figure 2 Anteroposterior and right oblique three-dimensional CT reconstruction of the proband's skull at the age of nine months, demonstrating synostosis of the right coronal suture. Note ridging along the line of the involved suture (arrow). The metopic, sagittal and left coronal sutures are patent (arrowheads).

\section{Discussion}

The presence of the Ala315Ser mutation in FGFR2 in three members of this family, only one of whom has overt craniosynostosis, and none of whom has Crouzonoid facial features, raises the question as to whether this mutation has predisposed to the craniosynostosis or is a coincidence.

The context in which the mutation occurs is illustrated in Figure4. The $G \rightarrow T$ transversion occurs at the fourth nucleotide of the alternatively spliced I gl IIc exon of FGFR2, which is the exon most commonly mutated in Crouzon and Pfeiffer syndromes. ${ }^{1,2}$ A cluster of mutations has been described in theintron just upstream of the Iglllc exon (Figure4); all these mutations are associated with either Pfeiffer or Apert syndrome. ${ }^{20,22-29}$ These mutations are predicted to affect correct recognition of the Iglllc acceptor splice site, and in three cases, alternative use of the Iglllb exon has been demonstrated. ${ }^{20}$ Several $G \rightarrow T$ transversions, all associated with Pfeiffer syndrome, have been described in the first nucleotide of the Iglllc exon. ${ }^{23,30}$ These are predicted to encode an Ala314Ser substitution; alternatively, their predominant pathogenic effect may be on splicing. This has not been investigated experimentally, but the first nucleotide of the exon forms part of the acceptor splice site consensus, with $G$ being the most common nucleotide $(49.7 \%$ in mammals) and $T$ being the least common $(9.8 \%){ }^{31}$ Mutations at this position of the splice site are rare, ${ }^{32}$ but an exactly equivalent mutation in the dihydrofolate reductase gene has been shown to affect splicing in cultured cells. ${ }^{33}$ However, it is very unlikely that the $943 \mathrm{G} \rightarrow \mathrm{T}$ mutation that we have identified acts in a similar fashion, both because it lies outside the acceptor splice consensus and because fibroblasts from the proband do not exhibit any ectopic expression of the Iglllb exon (data not shown). The closest mutation downstream of Ala315Ser described to date is the substitution Asp321Ala, located in a short $\alpha$-helical (D) segment ${ }^{34-36}$ and identified in four cases of Pfeiffer syndrome.22,27,37 No experimental studies have directly addressed the pathologic mechanism of this mutation, but disruption of the immunoglobulin fold leading to covalent dimerisation and constitutive activation of FGFR2 is the mechanism by which other mutations of the Iglllc domain are believed to act. ${ }^{38}$

Several lines of evidence argue against the Ala315Ser mutation having a similarly gross disruptive effect. First, the substitution is relatively conservative: the side chains of alanine and serine have similar polarity and molecular volume. ${ }^{39}$ Second, this residue lies on the surface of the IgllI 


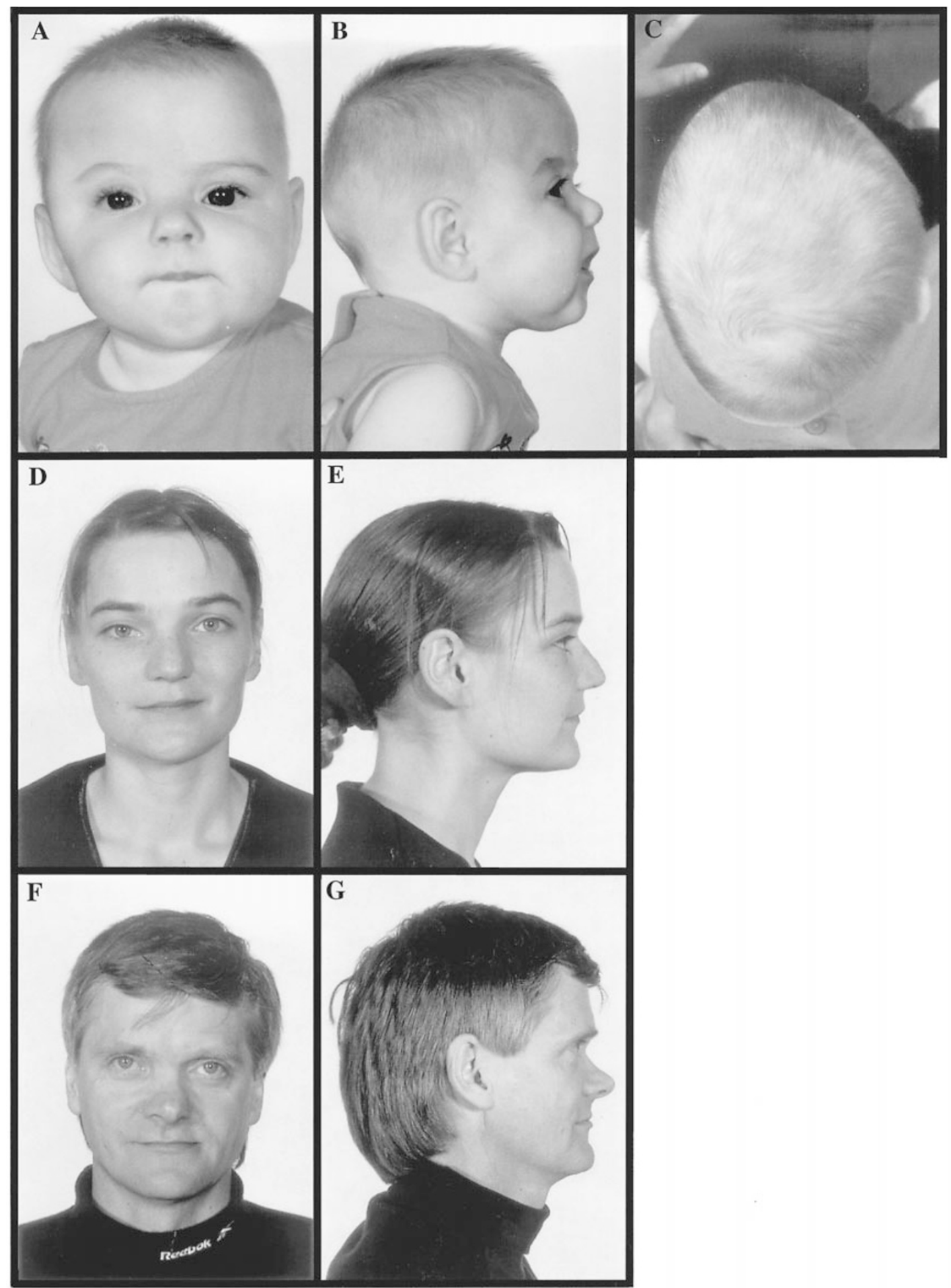

Figure 3 Clinical photographs of the proband (A, B, C) aged six months, her mother (D, E) and maternal grandfather (F, G). Note the absence of typical Crouzonoid features in all three subjects, and the normal thumb visible in the proband (C).

domain between the $C^{\prime}$ strand and $D$ helix, a region which is involved in ligand binding; ${ }^{34-36}$ hence the mutation is unlikely to disrupt the tertiary structure of the protein. Third, the alternatively spliced Iglllb exon encodes a serine at the 


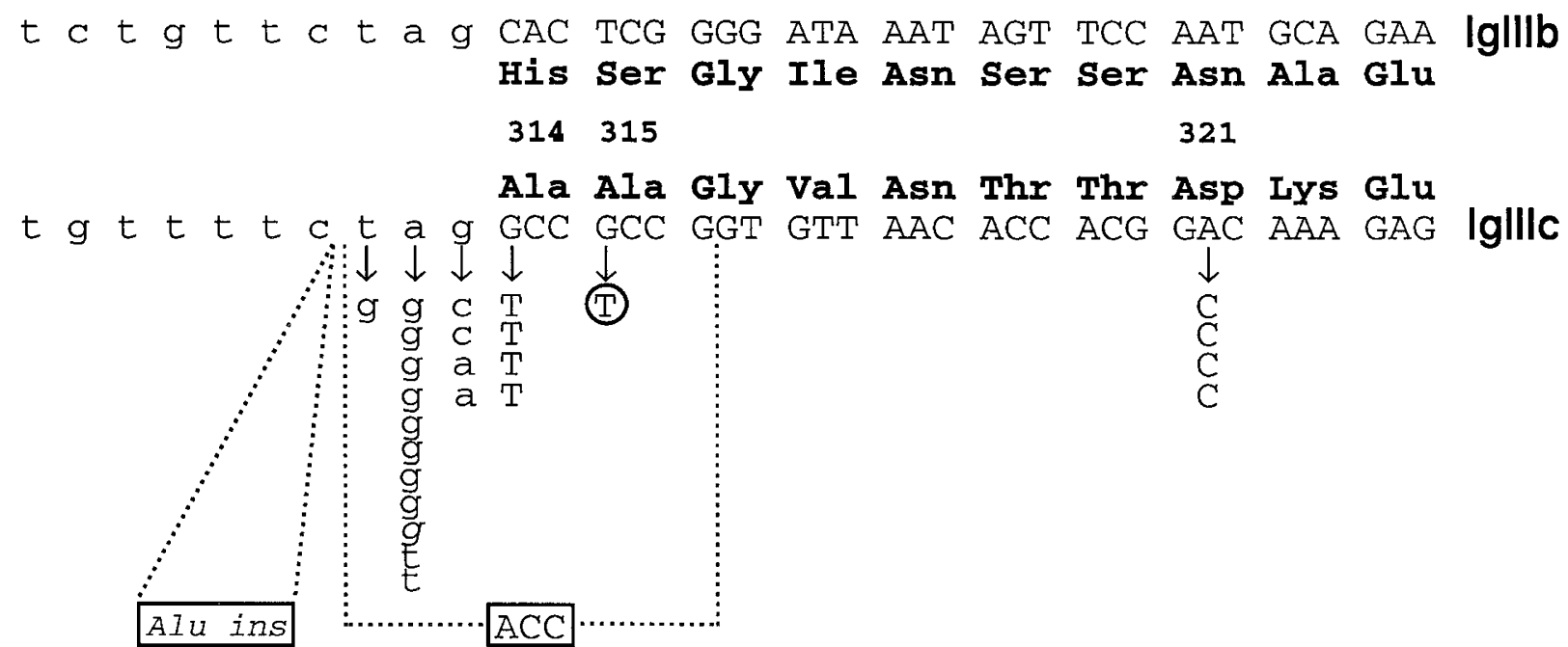

Figure 4 Genomic sequence of FGFR2 showing the position the Ala315Ser mutation (circled) in the context of neighbouring mutations. Intron sequence is shown in lower case; exon sequence in upper case. The upper nucleotide sequence encodes the Iglllb isoform whereas the lower sequence encodes the Iglllc isoform. The corresponding amino acid sequences are shown in bold and key amino acid sequences are numbered individually. Below the lglllc nucleotide sequence, downpointing arrows or dotted lines show the position of all reported mutations, which are identified individually. Two complex mutations (an Alu insertion and an insertion/deletion) are denoted by rectangles. All mutations have been associated with Pfeiffer syndrome except two cases of Apert syndrome (italicised mutations) and the mutation described in the current report. Note the presence of serine at codon 315 in the alternatively spliced Iglllb exon.

equivalent position (Figure4) demonstrating that the substituted amino acid is compatible with normal function in a slightly different amino acid sequence context.

Given the above arguments, it might be concluded that Ala315Ser is a neutral polymorphism. However, the alanine residue has been conserved in all IgllIc/FGFR2 vertebrate sequences examined including mouse, frog, newt and chicken ${ }^{40}$ and we were unable to identify this substitution in normal individuals despite screening over 1000 chromosomes. We also observed subtle facial abnormalities (hypertelorism, dystopia canthorum) in II-2 and III-2, but not overt craniosynostosis. These observations are consistent with the mutation exerting a weakly pathogenic effect.

The proband, in addition to inheriting the Ala315Ser mutation, had an abnormal intrauterine history. A persistent breech presentation was apparent from 34 weeks gestation. The initial documentation of hip flexion associated with the breech position, together with the immediate postnatal finding that the feet were pressed against the right side of the patient's head, imply that significant intrauterine foetal head constraint had occurred. The importance of foetal head constraint in the aetiology of craniosynostosis is attested to both by anecdotal reports ${ }^{13-16}$ and experimental studies in animals. ${ }^{17}$ This environmental factor, occurring in the context of an existing Ala315Ser mutation, offers a plausible explanation for why craniosynostosis occurred only in the proband, al though the mutation had previously been transmitted over at least two preceding generations. This highlights the role of non-genetic factors in ultimately determining phenotype.
Our observation raises the difficult issue of how we should counsel this family. Given the small sample size and inherent ascertainment bias, it is impossible to provide an accurate estimate of the risk of craniosynostosis associated with inheritance of the Ala315Ser mutation. Five other healthy children are at $50 \%$ risk for carrying the mutation (Figure $1 \mathrm{~A}$ ); it has been decided, however, that determination of their genetic status will not be offered until they are old enough to give informed consent. The identification of further families segregating this mutation would help to clarify its clinical implications.

\section{Acknowledgements}

We thank the family for their help with this study, S Robertson for comments on the manuscript, $\mathrm{P}$ Anslow for help in interpreting radiographs, $\mathrm{K}$ Nakai for information from his splice site mutation database, SJL Knight for access to control samples, S Butler for cell culture and DJ Weatherall for support. This work was funded by Wellcome Trust awards to DJ and AOMW.

\section{References}

1 Wilkie AOM: Craniosynostosis: genes and mechanisms. Hum Mol Genet 1997; 6: 1647-1656.

2 Muenke M, Wilkie AOM: Craniosynostosis syndromes. In: Scriver CR, Beaudet AL, Sly WS, Valle D, Vogelstein B, Childs B (eds). The Metabolic and Molecular Basis of Inherited Disease. McGraw-Hill: New York, 2000 (in press), ch 245.

3 Johnson DE, Lu J, Chen H, Werner S, Williams LT: The human fibroblast growth factor receptor genes: a common structural arrangement underlies the mechanism for generating receptor forms that differ in their third immunoglobulin domain, 8th edn. Mol Cell Biol 1991; 11: 4627-4634. 
4 Miki T, Bottaro DP, Fleming TP et al: Determination of ligandbinding specificity by alternative splicing: Two distinct growth factor receptors encoded by a single gene. Proc Natl Acad Sci USA 1992; 89: 246-250.

5 Bellus GA, Gaudenz K, Zackai EH et al: Identical mutations in three different fibroblast growth factor receptor genes in autosomal dominant craniosynostosis syndromes. Nat Genet 1996; 14: 174-176.

6 Meunke M, Gripp KW, McDonald-McGinn DM et al: A unique point mutation in the fibroblast growth factor receptor 3 gene (FGFR3) defines a new craniosynostosis syndrome. Am J Hum Genet 1997; 60: 555-564.

7 Moloney DM, Wall SA, Ashworth GJ et al: Prevalence of Pro250Arg mutation of fibroblast growth factor receptor 3 in coronal craniosynostosis. Lancet 1997; 349: 1059-1062.

8 Jabs EW, Li X, Scott AF et al: The Jackson-Weiss and Crouzon syndromes are allelic with mutations in fibroblast growth factor receptor 2. Nat Genet 1994; 8: 275-279.

9 Pulleyn LJ, Reardon W, Wilkes D et al: Spectrum of craniosynostosis phenotypes associated with novel mutations at the fibroblast growth factor receptor 2 locus. Eur J Hum Genet 1996; 4: 283-291.

10 Steinberger D, Reinhartz T, Unsöld R, Müller U: FGFR2 mutation in clinically nonclassifiable autosomal dominant craniosynostosis with pronounced phenotypic variation. Am J Med Genet 1996; 66: 81-86.

11 Oldridge M, Lunt PW, Zackai EH et al: Genotype-phenotype correlation for nucleotide substitutions in the Igll-Iglll linker of FGFR2. Hum Mol Genet 1997; 6: 137-143.

12 Everett ET, Britto DA, Ward RE, Hartsfield JK: A novel FGFR2 gene mutation in Crouzon Syndrome associated with apparent nonpenetrance. Cleft Palate Craniofac J 1999; 36: 533-541.

13 Graham JM Jr, deSaxe M, Smith DW: Sagittal craniostenosis: fetal head constraint as one possible cause. J Pediatr 1979; 95: 747-750.

14 Graham JM Jr, Badura RJ, Smith DW: Coronal craniosynostosis: fetal head constraint as one possible cause. Pediatrics 1980; 65: 995-999.

15 Graham JM Jr, Smith DW: Metopic craniostenosis as a consequence of fetal head constraint: Two interesting experiments of nature. Pediatrics 1980; 65: 1000-1002.

16 Higginbottom $\mathrm{MC}$, Jones $\mathrm{KL}$, James $\mathrm{HE}$ : Intrauterine constraint and craniosynostosis. Neurosurgery 1980; 6(1): 39-44

17 Koskinen-Moffett L, M offett BC: Sutures and intrauterine deformation. In: Persing JA, Edgerton MT, Jane JA (eds). Scientific Foundations and Surgical Treatment of Craniosynostosis, Williams and Wilkins: Baltimore, 1989; pp 96-106.

18 Wilkie AOM, Slaney SF, Oldridge $M$ et al: Apert syndrome results from localized mutations of FGFR2 and is allelic with Crouzon syndrome. Nat Genet 1995; 9: 165-172.

19 Twigg SRF, Burns HD, Oldridge $M$, Heath JK, Wilkie AOM: Conserved use of a non-canonical $5^{\prime}$ splice (/GA) in alternative splicing by fibroblast growth factor receptors 1,2 and 3. Hum $\mathrm{Mol}$ Genet 1998; 7: 685-691.

20 Oldridge $M$, Zackai EH, McDonald-McGinn DM et al: De novo Alu-element insertions in FGFR2 identify a distinct pathological basis for Apert syndrome. Am J Hum Genet 1999; 64: 446-461.

21 Dionne CA, Crumley $\mathrm{G}$, Bellot $\mathrm{F}$ et al: Cloning and expression of two distinct high-affinity receptors cross-reacting with acidic and basic fibroblast growth factors. EMBO J 1990; 9: 2685-2692.
22 Lajeunie E, Ma HW, Bonaventure J, Munnich A, Le Merrer M, Renier D: FGFR2 mutations in Pfeiffer syndrome. Nat Genet 1995 9: 108.

23 Schell U, Hehr A, Feldman GJ et al: Mutations in FGFR1 and FGFR2 cause familial and sporadic Pfeiffer syndrome. Hum Mol Genet 1995; 4: 323-328.

24 Hollway GE, Suthers GK, Haan EA et al: Mutation detection in FGFR2 craniosynostosis syndromes. Hum Genet 1997; 99: 251-255.

25 Passos-Bueno MR, Sertié AL, Richieri-Costa A et al: Description of a new mutation and characterization of FGFR1, FGFR2, and FGFR3 mutations among Brazilian patients with syndromic craniosynostosis. Am J Med Genet 1998; 78: 237-241.

26 Anderson PJ, Hall CM, Evans RD, Jones BM, Hayward RD: The feet in Pfeiffer's syndrome. J Craniofac Surg 1998; 9: 83-87.

27 Cornejo-Roldan LR, Roessler E, Muenke M: Analysis of the mutational spectrum of the FGFR2 gene in Pfeiffer syndrome. Hum Genet 1999; 104: 425-431.

28 Hedrich $\mathrm{K}$, Thiele $\mathrm{H}$, Rühl A, Hansman I, Hehr U: FGFR2 mutations in patients with Pfeiffer syndrome typellI. Am J Hum Genet 1999; 65 Suppl: A151.

29 Chun KM, Teebi A, Kennedy S, Forrest CR, Ray PN: Graduated strategy for the molecular diagnosis of craniosynostosis syndromes. Am J Hum Genet 1999; 65 Suppl: A289.

30 Mulliken JB, Steinberger D, Kunze S, Müller U: Molecular diagnosis of bilateral coronal synostosis. Plast Reconstr Surg 1999; 104: 1603-1615.

31 Senapathy $P$, Shapiro MB, Harris NL: Splice junctions, branch point sites, and exons: Sequence statistics, identification and applications to genome project. Methods Enzymol 1990; 183: 252-278.

32 Nakai K, Sakamoto H: Construction of a novel database containing aberrant splicing mutations of mammalian genes. Gene 1994; 141: 171-177.

33 Mitchell PJ, Urlaub G, Chasin L: Spontaneous splicing mutations at the dihydrofolate reductase locus in Chinese hamster ovary cells. Mol Cell Biol 1986; 6: 1926-1935.

34 Bateman A, Chothia C: Outline structures for the extracellular domains of the fibroblast growth factor receptors. Nat Struct Biol 1995; 2: 1068-1074.

35 Plotnikov AN, Schlessinger J, Hubbard SR, Mohammadi M: Structural basis for FGF receptor dimerization and activation. Cell 1999; 98: 641-650.

36 Stauber DJ, DiGabriele AD, Hendrickson WA: Structural interactions of fibroblast growth factor receptor with its ligands. Proc Natl Acad Sci USA 2000; 97: 49-54.

37 Nagase T, Nagase $M$, Hirose $S$, Ohmori K: Mutations in fibroblast growth factor receptor 2 gene and craniosynostotic syndromes in Japanese children. J Craniofac Surg 1998; 9: 162-170.

38 Robertson SC, Meyer AN, Hart KC, Galvin BD, Webster MK, Donoghue DJ: Activating mutations in the extracellular domain of the fibroblast growth factor receptor 2 function by disruption of the disulfide bond in the third immunoglobulin-like domain. Proc Natl Acad Sci USA 1998; 95: 4567-4572.

39 Grantham R: Amino acid difference formula to help explain protein evolution. Science 1974; 185: 862-864.

40 Coulier F, Pontarotti P, Roubin R, Hartung H, Goldfarb, Birnbaum D: Of worms and men: An evolutionary perspective on the fibroblast growth factor (FGF) and FGF receptor families. J Mol Evol 1997; 44: 43-56 